\title{
Levantamento retrospectivo de casos de escabiose canina e felina, atendidos na Faculdade de Medicina Veterinária e Zootecnia da Universidade de São Paulo, no período compreendido entre 1984 e 2002
}

\author{
Rita de Cássia Carmona Castro \\ Luiz Eduardo Bagini Lucarts ${ }^{1}$ \\ Ericka Homman Delayte ${ }^{1}$ \\ Mary Otsuka ${ }^{1}$ \\ Pedro Manuel Leal Germano ${ }^{2}$ \\ Carlos Eduardo Larsson ${ }^{1}$
}

Correspondência para: CARLOSEDUARDO LARSSON

Departamento de Clínica Médica Faculdade de Medicina Veterinária e Zootecnia da USP

Avenida Prof. Orlando Marques de Paiva, 87

Cidade Universitária Armando Salles de Oliveira

05508-270 - São Paulo - SP

larsderm@ hotmail.com

rita.carmona@ig.com.br

Recebido para publicação: 01/07/2003 Aprovado para publicação: 15/03/2005

\author{
1- Serviço de Dermatologia do Departamento de Clínica Médica e do \\ Hospital Veterinário da Faculdade de Medicina Veterinária e Zootecnia da \\ USP, São Paulo - SP \\ 2- Departamento de Práticas de Saúde Pública da Faculdade de Saúde \\ Pública da USP, São Paulo - SP
}

\section{Resumo}

Palavras-chave Sarnas.

Em levantamento retrospectivo de 19 anos (1984-2002), envolvendo a totalidade de 39524 casos dermatopáticos, de caninos e felinos, atendidos no Serviço de Dermatologia do VCM-HOVET/FMVZUSP, identificou-se um total de 2907 (7,3\%) casos de escabiose. Respectivamente, 2283 (78,5\%) e 624 (21,5\%) animais, eram das espécies canina e felina. A frequência de ocorrência da sarna sarcóptica $(6,4 \%)$ foi inferior àquela da sarna notoédrica $(15,7 \%)$, esta última, duas e meia vezes mais freqüente que a congênere canina, sendo tal diferença significativa $(\mathrm{p}<0,05)$. Relativamente, à predisposição sexual, os machos apresentaram maior suscetibilidade à infecção do que as fêmeas, em ambas as espécies. Quando da comparação dos sexos, entre caninos e felinos, observou-se que os animais da espécie felina são os atingidos com maior freqüência pela escabiose $(p<0,05)$. Ao se considerar a predisposição racial, apenas na espécie canina, constatou-se maior tendência de acometimento de animais de raça definida (58,0\%). As raças caninas (Poodle, Cocker Spaniel e Pastor Alemão) de pelame longo (74,2\%) e felina (Siamês) de pelo curto (81,3\%) foram as mais acometidas $(p<0,05)$. Animais com faixa etária inferior a um ano foram aqueles mais freqüentemente infectados (caninos 54,7\%, felinos $63,5 \%$ ) e dentre estes, foram os felinos os mais atingidos $(p<0,05)$. Não houve influência sazonal na ocorrência de escabiose, canina e felina.

\section{Introdução}

No cotidiano da clínica médica de pequenos animais, as dermatopatias representam cerca de $30 \%$ de todo atendimento clínico, independentemente da localização geográfica e do nível de desenvolvimento da região ou país considerado $^{1,2,3}$.

Dentre as diferentes enfermidades tegumentares que acometem os caninos e felinos domésticos, as dermatites parasitárias assumem um papel de extrema importância, não só pela magnitude de ocorrência, mas pelo potencial zoonótico inerente à algumas dessas ectoparasitoses. As dermatopatias parasitárias representam, em termos de busca de auxílio, pelo proprietário de cães e gatos, ao profissional clínico veterinário, um significativo percentil de casos. No Serviço de Dermatologia do Hospital Veterinário da USP, tais dermatites representaram, no período de 1985 a 1988, 20\% de todas as enfermidades tegumentares ali 
diagnosticadas ${ }^{4}$. Cerca de, respectivamente, $39,6 \%$ e $14,2 \%$, constituíam-se em casos de escabiose canina e felina ${ }^{5}$.

A grande magnitude de casos de sarnas animais decorrentes do parasitismo pelos ácaros do gênero Sarcoptidae, no Brasil, vincula-se, provavelmente, às condições climáticas, tipo de criação e, também, ao padrão sócio-econômico e cultural dos proprietários.

O agente etiológico da escabiose animal e humana, é o Sarcoptes scabiei. Sua primo descrição foi feita no século 18 , por Degeer (1778), sendo a escabiose uma das primeiras doenças a ter sua etiologia plenamente esclarecida. Sarcoptes scabiei var. canis, agente eliciador da sarna sarcóptica, descrito pela primeira vez por Bourguignon (1853), pertence a família Sarcoptidade, assim como o ácaro Notoedris cati, causador da escabiose felina ou sarna notoédrica ${ }^{1}$.

Do ponto de vista da saúde pública sabe-se, de há muito, que as escabioses canina e felina, constituem-se em importantes antropozoonoses, acometendo os proprietários dos animais. Tem elas, ainda, caráter ergodermatósico, mormente em profissionais veterinários e tratadores de animais. São enfermidades estigmatizantes causando constrangimento e mal-estar àqueles por ela infectados.

A despeito disto, principalmente em países em desenvolvimento, onde grassam em maior magnitude, inexistem ou são escassos os trabalhos dispostos na bibliografia mundial, enfocando os seus aspectos epidemiológicos ${ }^{6,7,8}$.

A sarna sarcóptica ocorre, principalmente, nos cães com menos de um ano de idade, possivelmente pela mantença destes animais em canis de criação, destarte não se pode afastar o envolvimento de fatores imunológicos e a própria promiscuidade nas primeiras faixas etárias. Também fatores imunológicos podem estar envolvidos. Ainda, segundo Griffin ${ }^{8}$ e Carlotti e Bensignor ${ }^{6}$, aparentemente não há predisposição sexual ou racial, entretanto, outros autores norte-americanos referiram uma maior tendência de acometimento de algumas raças, mormente aquelas de pelame longo, que representam dois terços da casuística ${ }^{3}$.

Embora sejam muitos os trabalhos concernentes ao tema, dispostos tanto em literatura internacional como nacional, são escassos ou inexistem dados que caracterizem estas duas ectoparasitoses tanto clínico e principalmente, epidemiológicamente, nas condições brasileiras, inclusive no que tange uma possível sazonalidade de ocorrência.

Pela magnitude de ocorrência, potencial zoonótico e escassez de dados epidemiológicos relativos às escabioses canina e felina, na bibliografia, objetivou-se caracterizar epidemiológicamente, em série histórica de 19 anos, a casuística destas dermatites parasitárias, através de levantamento retrospectivo, determinando a incidência, sazonalidade, aspectos ezognósicos, de definição racial, etários e sexuais das ectoparasitoses em cães e gatos.

\section{Materiais e Métodos}

A amostragem foi composta pela totalidade de casos, de caninos e felinos, com diagnóstico etiológico firmado de escabiose, atendidos junto ao Serviço de Dermatologia do Departamento de Clínica Médica (VCM) e do Hospital Veterinário (HOVET) da Faculdade de Medicina Veterinária e Zootecnia da Universidade de São Paulo (FMVZ/USP), no período compreendido entre abril de 1984 e dezembro de 2002, ou seja, de 225 meses.

O levantamento da casuística foi realizado através da análise de fichas de registro diário de casos novos, atendidos no Serviço de Dermatologia, onde se dispunha, além do número de registro dos animais, dados acerca da espécie, definição racial e a raça, idade, sexo, comprimento de pelame e ocorrência segundo a estação do ano.

Computou-se para fins de quantificação dos casos segundo o comprimento de pelame, apenas os animais com plena definição racial. 
O diagnóstico de escabiose, segundo a rotina de atendimento no Serviço, foi estabelecido a partir dos dados da resenha, $\mathrm{da}$ anamnese, dos exames físico e dermatológico, complementados pelos exames subsidiários.

Aos resultados obtidos aplicou-se a distribuição normal com o Teste "Z", para duas médias independentes, com a finalidade de verificar a possível existência de diferenças entre as espécies canina e felina no que concerna a sexo e faixa etária. Aplicou-se, ainda, o Teste de duas proporções, com aproximação normal, para determinar a eventual existência de diferenças significantes entre: as freqüências de ocorrência das ectoparasitoses, em ambas as espécies; predisposição por sexo, pelame e definição racial. Para a determinação da possível influência sazonal na ocorrência das ectoparasitoses procedeu-se à análise de variância mediante o cálculo de experimentos em bloco casualizados. Adotou-se como níveis de rejeição $\mathrm{a}=0,05$ tanto no cálculo do valor crítico de "Z" de alfa quanto para os valores críticos de "F"19

Tabela 1 - Ocorrência (número e percentagem) de casos dermatopáticos e daqueles de escabiose em espécimens caninos atendidos no Serviço de Dermatologia VCM- HOVET / FMVZ - USP (1984 a 2002). São Paulo, 2003

\begin{tabular}{c|c|c|c}
\hline Ano & Casos Novos & Casos de Escabiose & $\%$ Escabiose \\
\hline 1984 & 401 & 12 & 3.0 \\
\hline 1985 & 768 & 16 & 7.9 \\
\hline 1986 & 1595 & 126 & 8.5 \\
\hline 1987 & 1714 & 146 & 6.0 \\
\hline 1988 & 1741 & 104 & 7.5 \\
\hline 1989 & 2098 & 158 & 7.1 \\
\hline 1990 & 2679 & 191 & 3.9 \\
\hline 1991 & 2641 & 103 & 6.3 \\
\hline 1992 & 2203 & 138 & 9.3 \\
\hline 1993 & 1758 & 164 & 6.8 \\
\hline 1994 & 1684 & 114 & 6.3 \\
\hline 1995 & 2287 & 143 & 8.9 \\
\hline 1996 & 2019 & 180 & 5.8 \\
\hline 1997 & 1855 & 107 & 6.0 \\
\hline 1998 & 2022 & 122 & 8,3 \\
\hline 1999 & 1929 & 161 & 5,4 \\
\hline 2000 & 2021 & 110 & 4,2 \\
\hline 2001 & 2054 & 88 & 4,6 \\
\hline 2002 & 2154 & 100 & 6,4 \\
\hline Total & 35623 & 2283 & $\ldots$ \\
\hline Média & 1874,9 & 120,2 & 47,2 \\
\hline Desvio padrão & 543,0 & & \\
\hline
\end{tabular}

Tabela 2 - Ocorrência (número e percentagem) de casos dermatopáticos e daqueles de escabiose em espécimens felinos atendidos no Serviço de Dermatologia VCM- HOVET / FMVZ - USP (1984 a 2002). São Paulo, 2003

\begin{tabular}{c|c|c|c}
\hline Ano & Casos novos & Casos de escabiose & $\%$ escabiose \\
\hline 1984 & 37 & 4 & 10,8 \\
\hline 1985 & 65 & 9 & 13,8 \\
\hline 1986 & 164 & 18 & 11,0 \\
\hline 1987 & 160 & 17 & 15,9 \\
\hline 1988 & 221 & 35 & 17,0 \\
\hline 1989 & 235 & 40 & 12,0 \\
\hline 1990 & 324 & 39 & 20,2 \\
\hline 1991 & 352 & 71 & 13,4 \\
\hline 1992 & 246 & 33 & 21,8 \\
\hline 1993 & 252 & 55 & 16,7 \\
\hline 1994 & 227 & 38 & 14,4 \\
\hline 1995 & 248 & 35 & 20,3 \\
\hline 1996 & 299 & 43 & 9,5 \\
\hline 1997 & 231 & 47 & 21,3 \\
\hline 1998 & 199 & 19 & 18,2 \\
\hline 1999 & 183 & 39 & 20 \\
\hline 2000 & 159 & 29 & 15,1 \\
\hline 2001 & 160 & 32 & $\ldots$ \\
\hline 2002 & 139 & 21 & $\ldots$ \\
\hline Total & 3901 & 624 & \\
\hline Média & 205,3 & 32,8 & 16,3 \\
\hline Desvio padrão & 79,3 & & \\
\hline & & & \\
\hline
\end{tabular}




\section{Resultados}

No período considerado de 19 anos foram atendidos 39524 casos dermatopáticos de cães (35623) e gatos (3901). Destes, foi estabelecido o diagnóstico de escabiose em 2907. Desses animais, respectivamente, 2283 $(78,5 \%)$ e $624(21,5 \%)$ eram das espécies canina e felina. Ou seja, atendeu-se em média cerca de 120 casos anuais de sarna sarcóptica e 32,8 casos de sarna notoédrica por ano de atendimento (Tabelas 1 e 2).

Dos cães escabióticos, 1202 (53,0\%) eram machos e $1066(47,0 \%)$ fêmeas. Em quinze $(0,65 \%)$ das fichas analisadas não se dispunha do sexo dos animais e, portanto, não foram eles aqui incluídos. Em relação aos felinos, pela análise da casuística, pôdese caracterizar o sexo em 606 (97,3\%), destes $353(58,3 \%)$ eram machos e $253(41,7 \%)$ fêmeas. Relativamente, à predisposição sexual, os machos apresentaram maior suscetibilidade à infecção do que as fêmeas, em ambas as espécies. Quando da comparação dos sexos, entre caninos e felinos, observou-se que os machos da espécie felina são os atingidos com maior freqüência pela infecção $(p<0,05)$. Portanto em ambas as espécies a escabiose foi mais freqüênte entre os machos.

Quanto a definição racial, constatouse que $1321(58,0 \%)$ cães eram de raça definida. Daqueles da espécie felina, 139 $(22,3 \%)$ tinham raça definida em contrapartida aos $485(77,7 \%)$ restantes, que não apresentavam precisa definição racial. Houve, portanto, maior acometimento de animais de raça definida apenas dentre os cães. As raças, dos cães acometidos, mais comumente observadas foram: Poddle (21,4\%), Cocker Spaniel $(17,6 \%)$ e o Pastor Alemão (15,9\%). Em relação aos gatos, animais das raças: Siamês $(82,8 \%)$, Persa $(14,8 \%)$, Sagrado da Birmânia $(1,6 \%)$ e, por fim, Himalaio $(0,8 \%)$ foram os mais representados.

Com relação ao comprimento do pelame, foram computados apenas dados relativos aos animais com precisa definição racial. Dentre os cães, 980 (74,2\%) apresentavam pelame longo e 341 (25,8\%) tinham-no curto. No que se refere a espécie felina, $113(81,3 \%)$ possuíam pelame curto e $26(18,7 \%)$ eram de pelame longo. Verificou-se diferença estatisticamente significativa $(\mathrm{p}<0,05)$ no que tange ao pelame longo e maior ocorrência das ectoparasitoses para a espécie canina e ao curto para a felina.

A faixa etária, respectivamente, para cães e gatos, variou entre dois e 192 meses e entre seis e 228 meses.

Dentre os animais de idade definida, na espécie canina, $1250(54,7 \%)$ tinham menos de 12 meses quando do surgimento do quadro de escabiose. Já entre os animais da espécie felina $382(63,5 \%)$ possuíam menos de um ano de vida quando do diagnóstico da enfermidade.

Em relação à sazonalidade de ocorrência da sarna sarcóptica, pôde-se observar que $553(24,2 \%)$ cães foram atendidos na primavera, $500(21,9 \%)$ cães no período de verão, $572(25,1 \%)$ no outono e por fim, $658(28,8 \%)$ no inverno.

No casos de felinos portadores de sarna notoédrica, $126(20,2 \%)$ foram atendinos na primavera, $145(23,2 \%)$ no período do verão, $169(27,0 \%)$ no outono e os restantes 184 (29,5\%) no inverno.

Pela análise das tabelas 1 e 2 , onde se dispõem a ocorrência de escabiose, canina e felina, frente as dermatopatias destes espécimens, ao longo das quatro estações do ano, pôde-se verificar que a casuística das sarnas, em comparação às outras dermatoses, comportou-se de modo similar ( $\mathrm{p}>0,05)$. Igualmente, pôde-se constatar que não houve influência sazonal na ocorrência de sarna sarcóptica e, tampouco, de sarna notoédrica ao longo dos 19 anos de observação.

\section{Discussão}

A magnitude da casuística da escabiose canina e felina ora reunida, da ordem de quase três mil casos, em interregno de dezenove anos de atendimento 
dermatológico em Serviço especializado, não pode ser cotejada face a inexistência de levantamentos deste naipe.

A incidência de $7,3 \%$ casos de escabiose (canina e felina), frente aos 39524 casos dermatopáticos novos, atendidos no Serviço, entre os anos de 1984 e 2002, retrata bem a importância que a ela deve ser dispensada pelos clínicos veterinários e pelos dermatologistas humanos face ao seu caráter zoonótico.

A despeito dos tratados de dermatologia ${ }^{10}$ humana enfocarem-na, no capítulo das dermatozooses, caracterizandoa como de surgimento em surtos e com tendência a desaparecer espontaneamente, em 12 a 14 dias, sabe-se, pelo cotidiano da clínica veterinária, que muitos dos dermatologistas humanos desconhecem a fácil e freqüente transmissão aos contactantes humanos, da ordem de 12 a 50\% dos casos. Ainda mais, consideram, aqueles profissionais, que pelo seu caráter autolimitante, no homem, seria desnecessária a interposição de terapia. Destarte, no caso de convivência e exposição contínua com os animais acometidos, ou seja há mais de 90 dias, (29\% dos casos) a enfermidade pode persistir por muito tempo, no mínimo reduzindo a qualidade de vida dos proprietários e demais contactantes.

As sarnas, sarcóptica e a notoédrica, ocupam um papel de destaque dentre todas as dermatopatias que acometem os cães e gatos. No presente estudo, verificou-se que a ocorrência destas ectoparasitoses foi da ordem de 6,4\% para a espécie canina e de $15,7 \%$ para a felina, considerando-se todos os casos novos atendidos no Serviço de Dermatologia (VCM-HOVET/FMVZUSP) em período de 19 anos. Estas magnitudes percentuais corroboram dados estatísticos pretéritos ${ }^{1,4,11}$ de que as dermatites parasitárias, dispõem-se, respectivamente, como a segunda e primeira causa de busca de atendimento ao Serviço pelos proprietários de cães e gatos dermatopatas.

Ao se cotejar os dados ora obtidos com os escassos trabalhos com este enfoque, dispostos na bibliografia estrangeira, verificase que a escabiose canina nos Estados Unidos da América do Norte é apenas a sétima dentre as dez dermatoses caninas mais freqüentes, segundo levantamento levado a cabo em 17 hospitais veterinários-escola daquele país, no ano de $1988^{3}$. Já, na França ${ }^{6}$, em um quadriênio, em termos de casos referidos, encaminhados a serviço de dermatologia privado, a escabiose canina foi diagnosticada em quatro por cento dos casos, ou seja, uma diferença de pouco mais de $30 \%$, relativamente à casuística paulista.

No que tange a espécie felina, também nos Estados Unidos da América do Norte, a sarna notoédrica é extremamente contumaz. Segundo inquérito promovido pela Academia Americana de Dermatologia Veterinária, há 23 anos atrás, a primeira das enfermidades tegumentares dos felinos era, também, a escabiose ${ }^{12}$.

Cotejando-se a proporção de casos de escabiose (Tabelas 1 e 2), em ambas as espécies, com a incidência das demais dermatoses, no período considerado, pôdese evidenciar que um a cada 15,6 cães atendidos estava acometido por Sarcoptes scabiei var. canis. Dentre os felinos, a sarna notoédrica foi duas e meia vezes mais freqüente que a congênere canina, pois a cada 6,2 gatos dermatopatas um estava infectados pelo Notoedris cati.

Em se enfocando a definição racial dos animais escabióticos, tão somente nos casos de sarna sarcóptica é que se verificou diferenças significantes, numéricas e percentuais. É perfeitamente sabido que a despeito de uma progressiva e cada vez maior opção de se adotar o gato como animal de companhia, pelo menos nos estados do sul e sudeste do Brasil, ainda a proporção de gatos sem precisa definição racial suplanta aquela de gatos ditos de raça. Inexistem trabalhos estrangeiros, sobre este aspecto epidemiológico, que permitam o cotejamento com os dados ora discutidos.

Quanto aos cães, observou-se que aqueles das raças Poodle $(21,4 \%$ de acometidos), Cocker Spaniel (17,6\%) e Pastor 
Alemão $(15,9 \%)$ foram os mais frequentemente atendidos em função da enfermidade. Esta distribuição racial dos animais escabióticos é exatamente idêntica àquela referida por Folz ${ }^{13}$ nos Estados Unidos da América do Norte. A somatória dos percentis de acometimento perfaz 55\% da casuística dos cães de raça definida. Afora este último autor, dentre os americanos ${ }^{12,14}$, apenas Sischo, Ihrke e Franti ${ }^{3}$, consideraram que, naquele país, as raças Labrador, Cocker Spainel e Dobermann constituem-se em raças de risco para a escabiose. Na França ${ }^{6,15}$, país com enorme população canina de raça definida não se observa qualquer predisposiçao racial. Relativamente aos felinos, as três raças mais acometidas (Siamês 82,8\%, Persa 14,8\% e Sagrado da Birmânia $1,6 \%)$ representam proporcionalmente a magnitude populacional das raças de gatos criadas em São Paulo. Inexistem, pela baixa incidência da sarna notoédrica nos demais países ${ }^{16}$, dados disponíveis para um esperado cotejamento.

A correlação da ocorrência de escabiose e o comprimento do pelame foi analisada, neste trabalho, em 50\% da amostragem, ou seja, apenas naqueles animais de raça definida. Tal como o já referido, tanto no Brasil ${ }^{1,4}$ como nos Estados Unidos da América do Norte ${ }^{12,13}$, os cães de pelame longo, foram os mais infectados, representando, praticamente, três quartas partes da amotragem.

Inexiste uma explicação plausível para esta díspar predisposição. Inclusive, paradoxalmente, afirmam Scott e Horn ${ }^{2}$ que os ácaros sarcoptídeos preferem muito mais as áreas glabras do tegumento (bordas de pavilhões auriculares, articulações úmerorádio-ulnares e tíbio-tarso-fibulares e abdomen) para sua proliferação.

No que tange à predisposição sexual evidenciou-se diferenças significativas entre sexo, em ambos os espécimens. Tal achado não corrobora assertivas dispostas em tratados clássicos de dermatologia veterinária e em artigos de periódicos ${ }^{1,4,6,9,12}$, pois, tanto em cães como gatos, evidenciou-se maior tendência, embora discreta, de acometimento de machos.

Até a década de 80, segundo Larsson ${ }^{1}$, evidenciava-se um nítido e maior acometimento, por sarna notoédrica, de machos felinos da ordem de quase $70 \%$. Para explicar a redução, ora constatada, permitese aventar como hipóteses: a atual tendência de criação dos felinos no interior do domicílio, principalmente, em prédios de apartamento; a modificação de hábitos, bem brasileiros, de permissividade de deambulação na vizinhança do domicílio dos gatos machos (animais querenciados ou vagantes); o procedimento da orquiectomia, cada vez mais recomendado e adotado, tornando o macho felino "menos promíscuo"e mais caseiro, tudo isto sem falar no sério risco de morte que correm os animais de serem atropelados em metrópoles como São Paulo.

Aparentemente não há predisposição sexual em relação à ocorrência de escabiose no homem. Há, no entanto, controvérsias quanto aos índices de infecção de pacientes do sexo masculino ou feminino ${ }^{17}$. Magnabosco e Prado ${ }^{17}$, consideraram que a maior tendência de ocorrência por um determinado sexo prender-se-ia à atividade ocupacional, ao nível sócio-econômico e aos hábitos culturais.

Ao se analisar a ocorrência da escabiose, relativamente à idade, tanto em cães como em gatos, pôde-se verificar naqueles com faixa etária definida (2834 animais ( 97,5\%) que a enfermidade foi diagnosticada em animais entre dois e 228 meses de idade (caninos- dois a 192 meses, felinos- seis a 228 meses). Esta ampla margem etária de acometimento permite caracterizar a enfermidade e o agente, respectivamente, como de altas morbidade e infectividade. $\mathrm{O}$ maior número de casos de escabiose canina (1250/57,3\%) e felina (382/ $63,5 \%$ ) situou-se no primeiro ano de vida. Este achado coaduna com aquele referido na totalidade dos trabalhos compilados ${ }^{1,3,4,6,9,12,13,14}$. Permite-se pressupor que a incidência maior em animais novos está 
relacionada a fatores imunitários, tal como o aventado por Gross, Ihrke e Walder ${ }^{18}$. No entanto, autores franceses ${ }^{6,8,15}$, recentemente, consideraram difícil interpretar tal predisposição para o assestamento da ectoparasitose pela superposição de fatores de risco. Dentre estes poder-se-ia considerar, a convivência em grupo, promiscuidade inata de cães e gatos jovens, inadequada auto higienização dos gatos, nos primeiros meses de vida e aos habituais erros de manejo. Ao se comparar com os trabalhos que precisam numericamente (número e percentagem) a ocorrência da escabiose no primeiro ano de vida, verifica-se que os valores, ora evidenciados, sobrepujam, em muito, aqueles observados na França ${ }^{6}$.

No gênero humano, segundo tratadistas e pesquisadores patrícios e estrangeiros, a idade não predispõe à ocorrência da escabiose ${ }^{10,17}$.

No que concerne a frequência de ocorrência segundo a estação do ano, à luz da análise estatística, o presente levantamento, revelou não haver influência sazonal na ocorrência da escabiose, canina e felina.

Entretanto ao se analisar, a distribuição da ocorrência das sarnas ao longo das quatro estações do ano, em números absolutos, observou-se uma maior incidência, embora muito discreta, nos meses de inverno (sarnas: sarcóptica $28,8 \%$ e notoédrica $29,5 \%$ ). Infelizmente, inexistem, na bibliografia especializada, trabalhos de mesmo cunho, em carnívoros domésticos, para o cotejamento. Há, no entanto, trabalhos espanhóis, realizados com caprinos, em que se afirma que a escabiose tem tendência sazonal, sendo mais frequêntes nos meses invernais ${ }^{16}$.

\section{Conclusões}

Em função da análise dos dados obtidos através do levantamento retrospectivo (1984-2002) dos casos de escabiose canina e felina, pode-se concluir que:

-a escabiose, canina (2283 casos) e felina (624 casos), representou 7,3\% da casuística dermatopática em período de 19 anos;

- o atendimento de casos de sarnas sarcóptica e notoédrica foi, respectivamente, da ordem de 120 e 32,8 casos/ano;

-a ocorrência das escabioses, canina e felina, relativamente as demais dermatoses foi da ordem, respectivamente, de $6,4 \%$ e $15,7 \%$, ou seja, a sarna notoédrica é duas e meia vezes mais freqüente que sua congênere;

-inexistiu predisposição à ocorrência de sarnas relativamente à sazonalidade, para ambas as espécies.

-houve predisposição à ocorrência a estas dermatoses relativamente: aos machos, de ambas as espécies, à faixa etária (igual ou menor a 12 meses de idade - caninos 57,4\% e felinos - 63,5\%), à indefinição racial dos felinos e ao comprimento do pelame (cães de pelame longo $74,2 \%$, gatos de pelame curto $-81,3 \%$

-as três raças mais acometidas, de cada uma das espécies, foram: caninos- Poodle, Cocker Spainel e Pastor Alemão; felinosSiamês, Persa e Sagrado da Birmânia.

\section{Canine and feline scabies in São Paulo - Brazil - Faculdade de Medicina Veterinária e Zootecnia da Universidade de São Paulo (1984-2002)}

\section{Abstract}

At the Veterinary Teaching Hospital (HOVET) in FMVZ/USP, sarcoptic and notoedric mange are the second and the third most commonly diagnosed parasitic skin diseases, respectively. Between 1984 and 2002, 2907 cases of canine and feline scabies were diagnosed at HOVET. Canine scabies (2283) and feline scabies
Key-words: Sarcoptic Mange. Notoedric Mange. Dogs.

Cats. 
(624) represented $6.4 \%$ and $15.7 \%$, respectively, of the cases seen. Feline scabies was more frequent than canine scabies $(\mathrm{p}<0.05)$. Canine scabies was more prevalent in pure breeds dogs $(58.0 \%)$ with long hair $(74.2 \%)$ and the most commonly affected dog breeds were: Poodle, Cocker Spaniel and German Shepherds. Canine and feline scabies were more frequent in males. Dogs (54.7\%) and cats $(63.5 \%)<12$ months old were the most affected. For notoedric mange stray cats, short-haired $(74.2 \%)$ were most commonly affected. Feline scabies was most common in Siamese, Persian and Burmese cat breed. There was no seasonal difference in the occurence of scabies in either cats or dogs when results were analysed.

\section{Referências}

1 LARSSON, C. E. Dermatologia Veterinária I. Sarna Sarcóptica. Comunicações Científicas da Faculdade de Medicina veterinária e Zootecnia da Universidade de São Paulo, v. 13, n. 1, p. 7-17, 1989.

2 SCOTT, D. W.; HORN, R. T. Zoonotic dermatoses of dogs and cats. Veterinary Clinics of North America: Small Animal Practice, v. 17, n. 1, p. 117-144, 1997.

3 SICHO, W. M.; IHRKE, P. J.; FRANTI, C. E. Regional distribution of ten common skin diseases in dogs. Journal of the American Veterinary Medical Association, v. 195, n. 6, p. 752-756, 1989

4 LARSSON, C. E. Dermatoparasitoses de cães e gatos: patogenia, diagnóstico diferencial e saúde pública. Revista Brasileira de Parasitologia Veterinária, v. 4, n. 2, p. 261-270, 1995.

5 NISHIMURA, E. S.; LEDON, A. L. P. B.; LARSSON, C. E. Relatório de atendimento diário do Serviço de Dermatologia do VCM/HOVET-FMVZ/USP. São Paulo: FMVZ, 1989.

6 CARLOTTI, D.; BENSIGNOR, E. La gale sarcoptique du chien: ètude rètrospective de 38 cas. Pratique Médicale \& Chirurgicale de L'anim de Compagnie, v. 32, n. 2, p. 117-127, 1997.

7 GAGUÉRE, E. Les gales des carnivores. In: COURS CES de Dermatologie Vetérinaire [s. I.]: École Veterinaire de Nantes, 1996.

8 BOURDEAU, P. Acariens et peau chez les carnivores In: Comptes-rendus du congrés annuel du GEDAC, 1993, Le Touquet. Proceedings... p. 178-190.

9 GRIFFIN, C. E.Scabies.In: GRIFFIN, G. E.; KWOCHKA, K. W.; MACDONALD, J. M. Current veterinary dermatology. St. Louis, Missouri: Mosby Year Book, 1993. p. 85-89.

10 RIVITTI E. A; SAMPAIO, S. A. P. Dermatozooses. In: Dermatologia. $2^{\text {a }}$ ed., [s. I.]: [s. n.], 2000. p. 575-590.

11 LARSSON, M. H. M. A. L.; HAGIWARA, M. K.; LARSSON, C. E.; KLOBUCARIC, A.; ENCARNAÇÃO,
M. L.; ANAYA, S. Ocorrência de sarnas demodécica e sarcóptica em cães do município de Sào Paulo, durante dez anos (1964/1973). Atualidades Veterinárias, v. 3, n. 3, p. 36-41, 1974.

12 NESBITT, G. H.; ACKERMANN, L. Canine Parasitic diseases.In: NESBITT, G. H; ACKERMAN, L. Canine and feline dermatology. New Jersey: ULS, 1998. p. 162-198.

13 FOLZ, S. D. Canine scabies infestation. Compendium on Continuing Education for the Practicing Veterinarian, v. 6, n. 3, p. 176-180, 1984.

14 MACDONALD, J. M.; Ectoparasites (canine scabies). In: Current veterinary therapy. VIII, KIRK, R. W. (Ed.), Philadelphia: W. B. Sauders, 1983.

15 CARLOTTI, D.; HÉRIPRET, D. La dermatite par allergie aux piqûres de puces chez le chien. Pratique Médicale \& Chirurgicale de L'anim de Compagnie, v. 31, n. 6, p. 1-64, 1996.

16 MORÁN, J. F.; GÓMEZ, S.; BALLESTEROS, F.; QUIRÓS, O. P.; BENITO, J. L.; FELIU, C.; NIETO, J. M. Epizootioloy of sarcoptic mange in a population of cantabrian chamois (Rupicapra pyrenaica parva) in Nortthwestern Spain. Veterinary Parasitology, n. 73, p. 163-171, 1997.

17 MAGNABOSCO, E. M.; PRADO, A. D. Fatores epidemiológicos de risco associados à escabiose. Annais Brasileiro de Dermatologia, v. 3, n. 73, p. 239-243, 1998.

18 GROSS T. L.; IHRKE, P. J.; WALDER, E. J. Veterinary dermatopathology. St. Louis: Mosby Year Book, Philadelphia, 1992.

19 ZAR, J. H. Biostatistical analysis. New Jersey: PrenticeHall, 1996. p. 14,124,211,212,502. 